\title{
TEENAGERS' KNOWLEDGE OF HUMAN SEXUALITY AND THEIR VIEWS ON TEENAGE PREGNANCIES
}

\author{
PJ Kunene
}

\begin{abstract}
There, s eoncern aboul poor knowtedge of human sexuality and a high rate of teenage pregnancies among blacks. The primary aim of the sudt) was to measure the knowledge that teenagers have on human sexwalify and to identify the sowrces from which they obtain such knowledge. The secondary aim was to deted how teenagers perceive the teentage pregnancy problem and its consequences.
\end{abstract}

A descriptive study was undertaken. Questionnotres were honded out and collected from 210 teenagers in two Sentor Secondary schools at a Black townstip near Empangeni.

The stidy revealed that teenagers have reasonable knowledge about the anatomy and devetopment of the reproductive organs at puberty but tacked sex counselling which resulted in their failure to understand the implicatians of sexuat behaviout. The tevel of knowledge and utitisation of the Youth Health Serices was found to be low the stidy atso reveated a high tevel of awar eness of the negative consequences of teenage pregnancies. The teenagers had numerous sitggestons to make for the prevention of teenage pregnancies.

\section{INTRODUCTION}

There is concern about poor knowledge of human sexuality among black teenagers and relevant education is not included in the school curricula. Minimal knowledge of the structure and development of reproductive organs is obtained through biology classes. Talk about sexuality between parents and their children is almost taboo.

There is also growing concern about teenagers who interrupt or do not complete their education because of unplanned pregnancies. The teenagers thus affected become mothers or fathers at an early age before they are physically, psychologically and emotionally ready for the experience of parenting. Numerous personal, family and community problems result from teenage pregnancies. Failure to cope with the demands of parenthood is a contributory cause of child abuse, child neglect and child abandonment.

\section{TEENAGERS' KNOWLEDGE OF HUMAN SEXUALITY}

The need to give sexuality education to children from as early as the age of ten has been recognised for many years. Teenagers deprived of appropriate knowledge are believed to be at risk of unplanned pregnancies. There are unfounded fears that providing sexuality education and information about contraception encourages early sexuality activity and promiscuity. On the contrary, research has shown that teenagers who know and understand the development of reproductive organs, especially the changes occurring at puberty, treat their bodies with respect. They become aware of the dangers of early sexual activity. Sexuality education is part of total health care; it is not giving permission nor encouraging sexual activity or promiscuity. It gives protection to the teenager, whereas ignorance leads to sexual dysfunction, abuse and unplanned teenage pregnancies (Sapire 1988:19-22).

Breakdown in traditional family lifestyles has deprived black teenagers of the sexuality education they used to get from their elder siblings. The modern trend of working mothers further diminishes open mother and daughter communication. Fathers away from home in search of work also leave their sons with no meaningful sexual guidance (Craig and Richter-Strydom, 1982:453). In a survey done in the Durban area in 1979 it was found that only 3 of 89 black children received sexuality education from their parents (Ross, 1979:22).

The Department of National Health and Population Development, in its concern about high teenage pregnancy rates and poor knowledge of youth on sexuality, introduced adolescent or youth health services which are separate from the family planning services utilised by adults. The aim of these services is to provide sex education and sex counselling to young people from as early as the age of 10 years.
The public is informed about these services through the media. Initial contact with young people is made through visits to school or other youth groups by the professional nurses and other youth health advisors employed in the service. In spite of the provision of these services the teenagers continue to be sexually active at an early age and high pregnancy rates persist.

\section{TEENAGE PREGNANCIES}

Ross (1979:22) reported on surveys done in the Durban area in 1979 which reflected that $18 \%$ of the total number of pregnancies occurred among teenagers. The rates varied among the various race groups, $20 \%$ among coloureds and blacks respectively, $17 \%$ among Indians and $14 \%$ among Whites. The report further stated that in one black township $89 \%$ of primigravidae were unmarried and under the age of 20 years.

To get a picture of the rate of black teenage pregnancies in the Empangeni area statistics of teenage deliveries during the years 1986 and $\mathbf{1 9 8 7}$ at the regional hospital for blacks were compared with the total number of deliveries. The teenage deliveries were $25 \%$ and $22 \%$ of total deliveries in 1986 and 1987 respectively. These rates showed no significant difference from the $20 \%$ black teenage pregnancy rate reported in the Durban area in 1979.

\section{DEFINITIONS}

In this study "sexuality education" refers to education or guidance which makes teenagers aware of their bodies particularly in respect of reproductive anatomy and physiology. "Sex counselling" is defined by the World Health Organization as "a process of helping individuals assimilate their sexual knowledge into fulfilling lifestyles and socially responsible behaviour" (Rigg, 1988:23).

\section{AIMS OF THE STUDY}

The primary aim of the study was to measure the knowledge that teenagers have on human sexuality and to identify sources from which they obtain such knowledge. The secondary aim was to detect how the teenagers perceived the teenage pregnancy problem and its consequences. It was also aimed at getting suggestions from the teenagers themselves on 
how such pregnancies can be minimised or prevented. It was envisaged that the study would provide educators with a data base on which to plan for future human sexuality education. It would also make the teenagers aware of the concern of society about pregnancies among very young people.

\section{LITERATURE REVIEW}

A survey of literature revealed that most studies in this field in KwaZulu-Natal had been done in the Durban and surrounding areas. No studies of this kind had been carried out in the Empangeni area which was selected for study.

Craig and Richter-Strydom (1982) studied unplanned pregnancies among urban Zulu schoolgirls at high schools in the Durban area as well as pregnant teenagers at various clinics. The study was aimed at determining factors associated with teenage pregnancies. Strong peer pressure, breakdown of institutions of the past which were responsible for sex socialisation, and widespread ignorance and misconceptions about contraceptive use were highlighted. Low socio-economic status of blacks which forced people to live in sub-standard, overcrowded conditions was also cited. Some girls sold sex to older men in exchange for money.

Rigg (1983:23) examined legal aspects which exist in regard to sexual relationships and use of contraceptives for minor women. She highlighted that it is illegal for a man to have sex with a girl under the age of 16 years and emphasis was placed on the importance of educating male adolescents about this. According to the Child Care Act (74 of 1983) the parental consent must be obtained before presenting contraceptives to a minor below the age of 18 years. The question to ask is "If she is already sexually active, does she not need protection against pregnancy?" Synton (1987:36) describes a case where contraceptives were refused to a girl of 14 years because her mother who was very religious did not give permission. The girl, because she was already sexually active, ended up with a pregnancy which could have been prevented.

Keogh (1988:30) found that teenagers are more at risk of unplanned pregnancies if they communicate poorly with parents, resent authority, perform poorly at school and generally have a low self-esteem. They are exposed to a sexual environment through the mass media at an early age.

The nurse has an important role to play in this field. She acts as counsellor and decision-maker. She must guard against value bias rooted in her own cultural or religious background. Some nurses have been known to resist giving teenagers contraceptives because they believe it encourages pre-marital sexual relationships (Thompson and Thompson, 1981:58-59; Welman, 1986:38).

\section{THEORETICAL FRAMEWORK}

The study was based on Dorothy Johnson's Behaviourial Systems model. Johnson describes man as a behaviourial system identified by his or her actions and behaviour which are regulated by biological, psychological and sociological factors. Man is seen as being made up of interrelated parts or subsystems which interact with the environment, influence and are influenced by it. Activities of the subsystems are continually changing as the person matures, learns and gains experience. The theory has relevance for this study because teenagers' behaviours are changing constantly as they mature, learn and gain experience. It therefore is necessary to guide and educate teenagers on sexuality matters as they move towards adulthood and maturity.

\section{RESEARCH METHODOLOGY}

\section{Research design}

A descriptive study was done. This made it possible to collect large quantities of data on teenagers' perceptions and attitudes about sexuality and teenage pregnancy problems.

\section{Population and sample}

In consideration of the fact that teenagers are scattered over a wide area it was decided to select a sample from two senior secondary schools in one of the black townships near Empangeni. The schools had an enrolment of 1500 and 980 students respectively. They were selected because they have a population mainly of teenagers, have identical classes from standard 6 to standard 10, and are close to each other. Cormack (1984:201) suggests that geographically close areas must be utilised for the planned research project because time and financial resources are limited.

Stratified random sampling was done. The two strata consisted of boys and girls in the $12-19$ age groups. It is important to study both groups because the boys and girls experience sexuality differently, and it is assumed that they have different or opposing views about sexuality, responsibility for, and consequences of teenage pregnancies. The total sample was 210 respondents, comprising 110 girls and 100 boys. This was considered to be a fair representation of both sex groups.

\section{Research instrument and data collection}

The research instrument used was a questionnaire which contained both open and closed-ended questions. It was designed according to the aims and objectives of the study. Face and content validity was checked by a research expert. The instrument was pre-tested on 20 students from another senior secondary school in the same area. Relevant modifications were made and the final questionnaire had a total of 30 questions. It was divided into four sections as follows:
Section 1: Personal, social and religious backgrounds.

Section 2: Knowledge of available adolescent or youth health services, attitudes towards them and degree of utilisation.

Section 3 Knowledge of development of reproductive organs.

Section 4: Awareness of, and views on teenage love relationships and consequences of teenage pregnancies.

The questionnaire was distributed personally to the respondents after having obtained permission from the school principals and informed consent from the selected respondents. The disappointment expressed by the students not selected to the sample demonstrated an interest, awareness and concem about human sexuality matters.

\section{DATA ANALYSIS AND FINDINGS}

\begin{tabular}{|lcc|}
\hline \multicolumn{3}{|c|}{ TABLE 1. Age distribution } \\
according to sex \\
$\begin{array}{l}\text { Age group } \\
\text { (years) }\end{array}$ & Females & Males \\
$12-13$ & $10 \%$ & $7 \%$ \\
$14-15$ & $12 \%$ & $14 \%$ \\
$16-17$ & $51 \%$ & $52 \%$ \\
$18-19$ & $27 \%$ & $27 \%$ \\
& $100 \%$ & $100 \%$ \\
\hline
\end{tabular}

Table 1 reflects that the majority of the respondents fell into the 16 to 19-year age group. It is important to study these age groups because statistics have shown that they are at highest risk of teenage pregnancies in comparison to the 13 to 15 -year age group.

Residential area, religious denomination, family structure

Sixty-three percent of the respondents lived in the township and $37 \%$ lived in the nural area. This variable and religious denomination yielded no significant differences in responses. Family structure was mostly nuclear, mothers being the people available to the majority of teenagers $(86 \%)$. This emphasizes the need for open communication between mothers and the teenagers.

\section{Hobbies}

The item on how teenagers spend their leisure time was included bocause it is believed to be the time when they are most exposed to various influences and peer pressures. Listening to music on radio and sport were the most commonest hobbies. Television was not available to those respondents who lived in rural areas. Those living in townships indicated they watched various programmes on television, including love and sex-oriented films. 
TABLE 2: Views on separation of youth health service from family planning services utilised by adults

Support separation

opposed to separation

Undecided
Females

$74 \%$

$7 \%$

$29 \%$

$100 \%$

Males
$54 \%$
$8 \%$
$38 \%$
$100 \%$

Total Group

$61 \%$

$7,1 \%$

$31,9 \%$

$100 \%$

\section{INFORMATION ON YOUTH HEALTH}

\section{Awareness of the youth health centre}

Sixty percent of the males and $45 \%$ of the females were not aware of the existence of the youth health centre in the Empangeni area. This high percentage of males who were not aware correlated with the general belief that the fermales should take more precautions about sexuality matters than males. The low level of awareness caused concern because the centre had been in existence for three years prior to the time of the research and the personnel of the youth health centre had visited the schools in the area to explain its nature and purpose.

Extent of utilisation of the youth health centre

This section was answered only by those who were aware of the existence of the youth health centre. The degree of utilisation was found to be low, only $26 \%$ of the females and $23 \%$ of the males.

\section{Reasons for not utilising the centre}

Respondents in the $12-15$ age groups expressed a feeling that they had no sexuality problems and therefore saw no need to utilise the centre. This is in contrary to the emphasis laid by Sapire (1988:19) on the need to give sexuality education from as early as 10 -years of age. Pregnancies occurring below the age of 12 years, though very rare, have been recorded. One girl in this age group stated that she would be embarrassed to be seen by her peers visiting the centre. This highlighted that the centre had negative connotations which had to be corrected. SERVICES

Respondents in the 16 to 19-year age group cited the inconvenience of the centre as their main reason for not utilising it. Eighty percent stated that it was too far away, they did not know how to get there and they needed money for transport. They would have preferred the centre to be in the township where they lived and not in town. This is in accordance with the principles of Primary Health Care which emphasise the importance of providing service close to where the people live in order to ensure accessibility, acceptability and optimum utilisation (De Haan, 1983:5). The hours of service in the centre clashed with school-time. Some indicated that they were shy to voice their personal concerns and problems to strangers. A few stated that their mothers were uninterested or refused to give them permission to visit the centre.

\section{Benefits of using the youth health centre}

Ninety-four percent of the girls stated that they benefited by being taught how pregnancy occurs and how it can be prevented. This was found to be thought-provoking because, according to personnel at the centre, teaching on pregnancy prevention per se was a low priority compared to sexuality education in general. An important question to be asked is "Do the teenagers see any relationship between good human sexuality education and prevention of teenage pregnancies?"

Eighty-nine percent of the boys indicated the benefit of good sexual advice and information on dangers of sexual relations with many partners. They also found it easier to discuss sexual issues with unknown people. Thirty-three percent expressed the belief that at the youth health centre they were told the truth about sex, which parents were ashamed to tell.

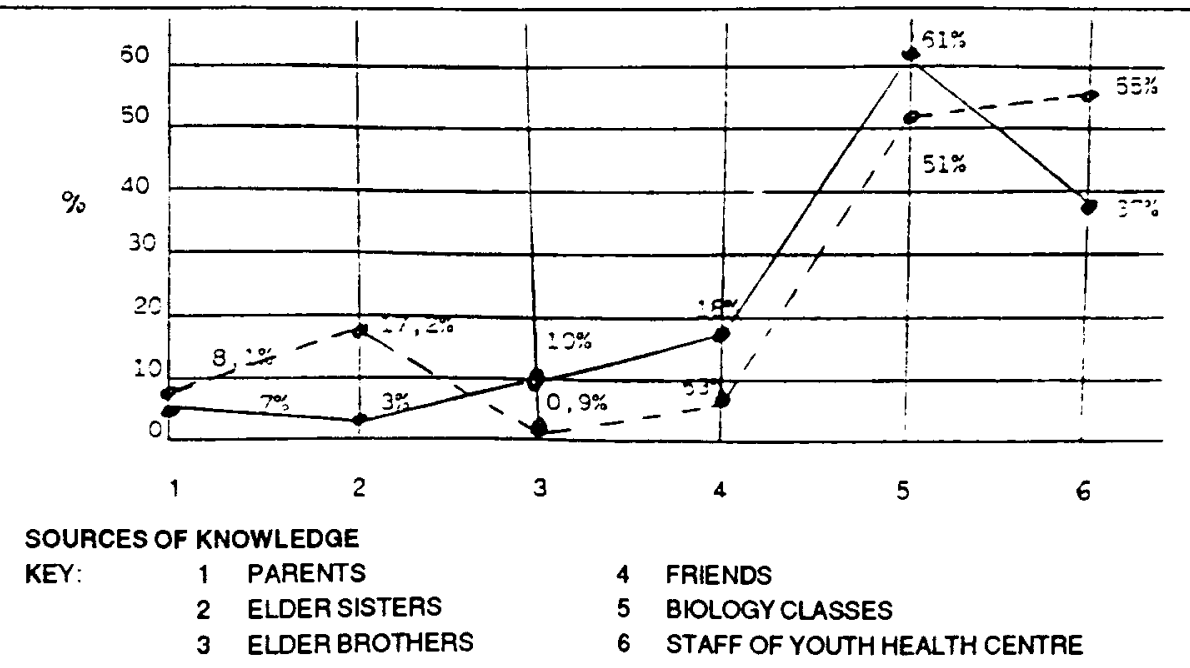

Figure I-Sources of knowledge of structure and development of sex organs
Opinions on how the service is rendered at the youth health centre

The respondents had some positive and negative opinions on how the service is rendered. This variable was included because utilisation is influenced by how one perceives the service offered.

The positive aspects included that they were allowed to talk about their personal feelings and make their own decisions on sexual matters. They were also treated with respect and not criticised for their behaviour.

The negative aspect highlighted most was lack of privacy as there was more group than individual guidance. This was seen as significant in view of the shyness expressed by some of those who did not utilise the centre.

Table 2 shows that the majority of both boys and girls $(61 \%)$ prefer having their own youth health services. Only $7,1 \%$ were opposed to separation of the services.

Views expressed by the females and males who were in favour of separation included that they did not want to mix with parents, parents are embarrassed to see their daughters at family planning services, the young people feel free to ask questions and take decisions without parents. They also stated that some adults like to gossip. The problems of teenagers are different from those of adults and therefore have to be catered for differently.

Those who were opposed to separation of the services highlighted feelings of insecurity when separated from parents on such sensitive issues. Parents could be told about problems of the youth by objective people at the family planning services. They also felt that people of the same gender experience similar sexual problems regardless of age, so there should be no secrets.

\section{KNOWLEDGE OF STRUCTURE AND DEVELOPMENT OF SEXUAL ORGANS}

The structure and development of reproductive organs was adequately understood, as were changes occurring at puberty. Fifty-five percent of the respondents knew what pertained to both sex groups.

Figure 1 indicates that biology classes are the most important source of knowledge followed by information from the staff of the youth health centre.

Early signs of pregnancy were well known in the 16 to 19-year age group. The majority $(88,5 \%)$ felt that it is important to give teenagers sexuality education before puberty in reached so that they know about menstruation and how to handle it, make correct decisions and protect themselves against unplanned pregnancies; $80,5 \%$ agreed that boys needed as much sexuality education as girls because they must both co-operate in taking responsible decisions. 


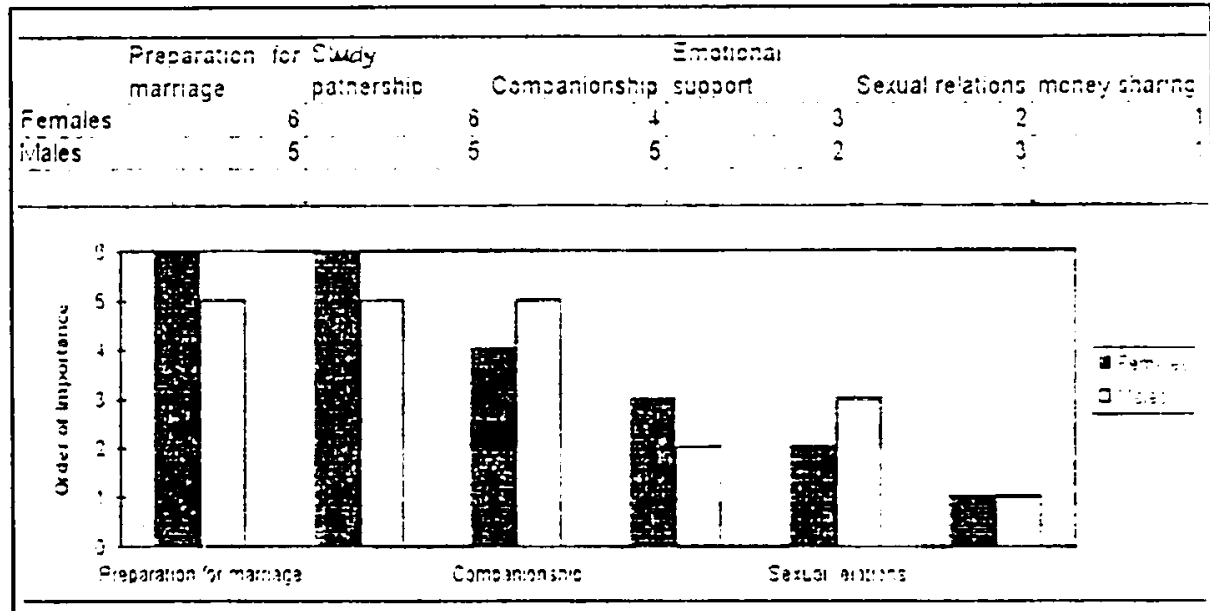

Figure 2: Rank order of reasons for teenage love relationships

\section{KNOWLEDGE ABOUT TEENAGE LOVE RELATIONSHIPS AND EFFECTS OF TEENAGE PREGNANCIES}

Of the respondents $92,2 \%$ were aware of love relationships among teenagers. They were asked to rank in order of priority the reasons for these relationships on a scale of 1 to 6 where one represented the least important, and 6 represented the most important reason.

Figure 2 shows that none of the respondents placed sexual relations at the top of the priority list. Preparation for marriage was most important to the girls while companionship was ranked as most important by the boys.

Opinions of teenagers on teenage sexual relations

Responses to these statements were graded on a Likert Scale. Only the percentage of those with who strongly agreed to each variable will be highlighted in this report.

It was noted that only a small percentage of boys (7\%) felt that there should be no indulgence in premarital sex while a large percentage (59\%) expressed the wish to have sexual experience. There was no significant difference in the percentage of girls who felt there should be no indulgence in premarital sex and those who wished to have sexual experience ( $28 \%$ and $21 \%$ respectively)

Views of teenagers on parents' guidance on sexuality matters

The majority (77\% girls and $64 \%$ boys) expressed a wish for their parents to discuss sexual matters freely with them. Seven percent of girls and $11 \%$ males felt that parents' guidance was useless because they did not understand the world of youth and they did not accept that the teenagers were old enough to make their own decisions.

Concern of teenagers about reactions to their behaviour

Teenagers were mainly concerned about parental disapproval of their behaviour, followed by that of their friends and peers. They were least concerned about disapproval by the teachers.

\section{Effects of teenage pregnancies}

The responses showed a high level of awareness of the negative consequences of teenage pregnancies. The following effects were highlighted by both boys and girls:

Effects on girls - have to leave school, fail to reach their goals, suffer financial difficulties, rejected by family and friends and are ignorant of the motherhood role and its responsibilities.

Effects on boys -have to leave school and work to support the mother and baby, unskilled for the labour market and may resort to deviant behaviour.

Effects on the baby - poor growth and development due to the parents' unpreparedness, later the child becomes embarrassed his illegitimate status.

Effects on the family - financial problems, anger, guilt, disappointment and embarr assment.

Effects on the conmunity - mistrust in the teenager, over-population, high rate of

Table 3: Opinions on teenage sexual relations

\section{Question}

1. No indulgence in premarital sex because it is sin.

$\begin{array}{rr}\text { Females } & \text { Strongly Agree } \\ \text { Males } \\ 28 \% & 7 \% \\ 27 \% & 28 \% \\ 21 \% & 59 \% \\ 4 \% & 27 \% \\ 6 \% & 20 \%\end{array}$

abandoned babies who become a burden to the state, loss of future leaders and professionals.

\section{SUGGESTIONS FOR PREVENTION OF TEENAGE PREGNANCIES}

Inclusion of this section was based on the premise that suggestions made by the teenagers themselves were acceptable to them and therefore would need consideration and close scrutiny for their safety, feasibility and possibility of success in preventing teenage pregnancies. The suggestions are summarised as follows:

- There is need for extensive human sexuality education by the parents as well as the schools starting education from the lower primary schools and by personnel of the youth health services.

- The government should provide more youth health centres which are easily accessible. Contraceptives, including condoms must be supplied freely at schools. Boys must be encouraged and supervised in the use of condoms.

- More recreational facilities are needed to keep the teenagers occupied. Preferably, there should be separate schools for boys and girls.

- Some felt that there should be no sexual activity among teenagers while others felt that teenagers should be allowed to practise sex but should be taught how and guided about the safe periods. It was also stated that girls must learn to control themselves because there will be no sex if they refuse.

\section{CONCLUSIONS}

The study revealed that awareness of the youth health centre was inadequate in spite of the personnel of the youth health centre having visited the schools. It was poorly utilised even by those who were aware of it and this was related mainly to the inconvenience caused by its unsuitable location. Most teenagers were in favour of separation of youth health services from family planning services used by adults. Parents do not take an active part in human sexuality education of their children even though most respondents indicated that they would value parental guidance on sexuality matters. The need for boys not to be neglected in this type of education was emphasised.

It was highlighted that love relationships do exist among teenagers but sexual relations are not their primary purpose, especially for the girls. The teenagers were aware of the negative consequences of teenage pregnancies.

\section{RECOMMENDATIONS}

A greater awareness of available youth health services must be created. Teachers, parents and all adults should have positive attitudes 
about them and motivate the teenagers to utilise them. Health planners must consider decentralisation of the services to make them readily accessible to the youth. More males should be employed in these services in order to lessen their feminine image and more boys should be encouraged to use them. More open communication between parents and their children should be encouraged with parents being given the necessary guidance.

The teenagers must be convinced that the best protection against teenage pregnancy is abstinence from sex. Those who have chosen to be sexually active must use some form of contraception based on sound professional advice and guidance.

Further research should be done on a wide scale and include the rural teenager not at school. Standardised evaluation tools should be developed to assess the effectiveness of the youth health services. The role of the church on values and values clarification regarding sexual activity should be investigated.

\section{REFERENCES}

Cormack, D.FS. (1984): The research process in nursing London: Blackwell Scientific Publications.

Craig, A.P. \& Richter-Strydom, L.M. (1984): Unplanned pregnancies among urban Zulu schoolgirls South African Medical Journal 19 March 1983: 453-455.

DeHaan, M. (1984): The health of Southern Africa $s^{\text {th }}$ edition. Wetton: Juta.

Keogh, J.(1988): Sex counselling of the male adolescent Par II - Family planning and the male adolescent Nursing RSA 10: 42-43.
Rigg, M. (1983): Counselling the sexually active teenager. Continuing Medical Education May 1983:22-27.

Ross, S.M. (1979): The unplanned teenage pregnancy Curationis, 2, 1, 22-23.

Sapire, K.E. (1988): Education for sexuality Nursing RSA 3 March 19-21.

Synton, L. (1987): Child mother blues Nursing Times 83,47, 36-37.

Thompson, J.B. \& Thompson, H.O. (1981): Ethics in Nursing New York: MacMillan

Welman,C.C.(1986): The South African nurse and family planning. Nursing R.S.A. February 1986: 36-39.

P.J. Kunene B.CUR (Hons.) Department of Nursing Science UNIVERSITY OF ZULULAND

\title{
CLOETE F, (1995). LOCAL GOVERNMENT TRANSFORMATION IN SOUTH AFRICA
}

\author{
PRETORIA: JL Schaik
}

This useful book by the well known and reputable author Fanie Cloete gives an outline of the transformation process in South Africa as it influences the current structure of local government. This reading is particularly useful for nursing educationists at a time when South Africa is in a state of political transition from apartheid to democracy. With the significant prioritisation of primary health care in the new health policy, it is essential that nurses have an understanding of local government structure and function. In the interim period of South African history this will serve as a quick reference for clarification of the new system. The book is well supported by annexures of recent legislation during 1993-1994 which are discussed in the main text.

A limitation is that the interim constitution is temporary and thus the long term use of this book lies in the historical record it gives of this time period. The pricing of the book will determine its accessability, as the main text consists of only thirty four pages', the remaining two thirds are made up of the relevant Acts.

Wendy Lewis

Department of Nursing UNIVERSITY OF NATAL 